\title{
Use of questionnaires in a study of spontaneous abortion in a general population
}

\author{
Gösta Axelsson
}

\begin{abstract}
Study objective-The aim was to evaluate the appropriateness of postal questionnaires in studies of spontaneous abortion in a general population.

Design-Survey of spontaneous abortions by comparing diagnoses reported in questionnaires to information collected from hospital records and a discharge register.

Setting-The study took place in the general community.

Participants-The study involved a random sample of 1400 women born between 1935 and 1960, living in two towns in the south west of Sweden.

Measurements and main results-9\% of spontaneous abortions among respondents were not reported in the questionnaire, and $31 \%$ were missing in the register; $80 \%$ of the spontaneous abortions reported in the questionnaire could be verified in hospital records, and a further $7 \%$ were mentioned in the records but not certified by a doctor; $97 \%$ of the diagnoses received by the women who had answered affirmatively to two complementary questions on spontaneous abortions could be found in the records.

Conclusions-Postal questionnaires can be used in epidemiological studies of spontaneous abortions, among a general population as well as among occupational groups.
\end{abstract}

A large number of epidemiological studies have been performed to assess the relationship between occupational exposures and pregnancy outcome. In a review of all such studies published between 1981 and 1985 Rosenberg et $a^{1}$ found many methodological weaknesses. Information on pregnancy outcome in all studies published between these years was collected retrospectively; in the majority of studies of spontaneous abortion, information was obtained through postal questionnaires or personal interviews.

In addition to the general problem of weak exposure data, several potential sources of bias may occur in studies of pregnancy outcome, such as selection bias ${ }^{2}$ and response bias. ${ }^{4}$ Recall bias is often discussed as a possible explanation for associations between exposure and outcome. ${ }^{56}$

Another potential bias is uncertainty in the diagnosis of spontaneous abortion. Spontaneous abortions reported in questionnaires were sought in hospital records in a previous study on pregnancy outcome among laboratory workers. In $88 \%$ of the cases, the diagnoses were either confirmed or found anamnestically in the records. ${ }^{7}$ Similar comparisons of self reported data on spontaneous abortion among some occupational groups and information available in hospital registers have been made in Denmark ${ }^{8}$ and Finland. ${ }^{9}$

As it is likely that spontaneous abortion will be studied in the future, not only among various occupational groups but also in relation to other environmental exposures, it is important to evaluate the use of postal questionnaires in such situations. Information on pregnancy outcome among non-respondents in a sample from a general population has not been presented previously, nor have data on spontaneous abortion in such a sample been compared to information in hospital records. The aim of this study was thus to evaluate the appropriateness of postal questionnaires in studies of spontaneous abortion in a general population by comparing the diagnoses reported in questionnaires to information in hospital records and a discharge register. A general comparison was also made between respondents and non-respondents regarding pregnancy outcome.

\section{Methods}

The study was based upon data from a study of pregnancy outcome among women living near petrochemical plants in Sweden. The relationship between living in the exposed area and the outcome of pregnancy has recently been published. ${ }^{10}$

Seven hundred women born between 1935 and 1960 and living in Stenungsund (34\% of the women in Stenungsund in this age interval) and 700 women born within the same time period living in Kungälv (29\%) were randomly selected from computerised lists based on birthdate obtained from the County Government Board.

In April 1982, the 1400 women were mailed a questionnaire on pregnancy outcome and exposure during pregnancy. A reminder was mailed three weeks later to those who had not responded, and a second reminder after an additional three weeks. Information was requested on all pregnancies, including induced abortions and ectopic pregnancies. Several questions were posed regarding exposure during the pregnancy. ${ }^{10}$ Questions regarding spontaneous abortion were posed concerning the time of their occurrence and whether the abortion had been verified by a physician.

Spontaneous abortions reported in the questionnaire were also sought in hospital records from departments of obstetrics and gynaecology. Information on gestational age and data on 
spontaneous abortion were obtained, in addition to information on hospital admission at the time of abortion. Records maintained at maternal health centres and hospital delivery wards were also investigated in order to collect information on addresses at the time of the pregnancy. At the same time, dissimilarities were covered between records and questionnaires with regard to number of pregnancies.

The national identity numbers of the 1400 women were linked to the Hospital Discharge Registry at the National Board of Health and Welfare to obtain information on hospital stay in the case of spontaneous abortions occurring between 1973 and 1981. At the time of the study, the register covered approximately $80 \%$ of Swedish women and included discharge diagnoses for all patients treated in hospital.

Information was available for each case on hospital, time of hospital admission, the municipality in which the woman lived at time of hospital admission, and a diagnostic code. This information was compared to data reported in questionnaires and hospital records.

Information on the number of pregnancies among non-respondents was obtained from records at the maternal health centres in Stenungsund and Kungälv and the delivery departments of the five hospitals in the region. For each pregnancy, information was collected on maternal age, year, outcome, and address. The review of records in this group was permitted by an ethics committee.

\section{Results}

In all, 1110 of the 1400 females responded to the questionnaire $(79.3 \%)$. The proportion of nonrespondents was slightly, but not significantly, higher in Kungälv than in Stenungsund, and was highest among women 35 years of age or older at the time of the distribution of the questionnaire.

Table I shows a comparison between respondents and non-respondents regarding the

Table I Distribution of pregnancies and children among respondents and non-respondents ( $R=$ respondents, $N-R=$ non-respondents).

\begin{tabular}{|c|c|c|c|c|c|c|c|c|}
\hline \multirow{2}{*}{$\begin{array}{l}\text { Age } \\
\text { (years) }\end{array}$} & \multicolumn{2}{|c|}{$\begin{array}{l}\text { Number of } \\
\text { pregnancies per } \\
\text { woman }\end{array}$} & \multicolumn{2}{|c|}{$\begin{array}{l}\text { Number of } \\
\text { children per } \\
\text { woman }\end{array}$} & \multicolumn{2}{|c|}{$\begin{array}{l}\text { Per cent } \\
\text { never } \\
\text { pregnant }\end{array}$} & \multicolumn{2}{|c|}{$\begin{array}{l}\text { Per cent } \\
\text { nulliparous }\end{array}$} \\
\hline & $R$ & $N-R$ & $\boldsymbol{R}$ & $N-R$ & $\boldsymbol{R}$ & $N-R$ & $\boldsymbol{R}$ & $N-R$ \\
\hline $\begin{array}{l}<25 \\
25-34 \\
\geqslant 35 \\
\end{array}$ & $\begin{array}{l}0.46 \\
1 \cdot 79 \\
2 \cdot 38 \\
\end{array}$ & $\begin{array}{l}0.84 \\
1.86 \\
2.88 \\
\end{array}$ & $\begin{array}{l}0 \cdot 32 \\
1 \cdot 34 \\
2 \cdot 04 \\
\end{array}$ & $\begin{array}{l}0.45 \\
1.44 \\
2.19 \\
\end{array}$ & $\begin{array}{r}71.9 \\
20.9 \\
9.3 \\
\end{array}$ & $\begin{array}{r}45 \cdot 2 \\
15 \cdot 3 \\
7 \cdot 7\end{array}$ & $\begin{array}{r}76 \cdot 6 \\
24 \cdot 1 \\
9 \cdot 9\end{array}$ & $\begin{array}{r}64 \cdot 5 \\
18 \cdot 7 \\
8 \cdot 9\end{array}$ \\
\hline
\end{tabular}

Table II Proportion of verified or anamnestically reported spontaneous abortions in relation to information in questionnaires

\begin{tabular}{llll}
\hline & $\begin{array}{l}\text { Number of } \\
\text { spontaneous } \\
\text { abortions } \\
\text { reported in } \\
\text { questionnaire }\end{array}$ & $\begin{array}{l}\text { \%o Verified } \\
\text { in hospital } \\
\text { records }\end{array}$ & $\begin{array}{l}\text { \%o Verified } \\
\text { or anamnestically } \\
\text { reported } \\
\text { in hospital } \\
\text { records }\end{array}$ \\
\hline $\begin{array}{l}\text { Total } \\
\begin{array}{l}\text { Positive pregnancy test } \\
\text { before miscarriage? }\end{array}\end{array}$ & 105 & 80 & 87 \\
$\begin{array}{l}\text { - Yes } \\
\begin{array}{l}\text { Doctor's confirmation? } \\
\text { - Yes }\end{array}\end{array}$ & 82 & 90 & 95 \\
$\begin{array}{l}\text { Positive pregnancy test } \\
\text { and doctor's confirmation? }\end{array}$ & 92 & 88 & 90 \\
\hline -Yes & 76 & 95 & 97 \\
\hline
\end{tabular}

distribution of pregnancies. The number of pregnancies per women and the number of children per woman was higher among nonrespondents in all three age groups. The proportion of women who had never been pregnant at the time of the study and the proportion of women who had never borne a child was higher among respondents in all age groups. The most striking difference was seen among women younger than $25: 71.9 \%$ of respondents and $45.2 \%$ of non-respondents had never been pregnant. The non-respondents-20.7\% of all women-correspond to $25.7 \%$ of all pregnancies in the study.

Spontaneous abortions were slightly, but not significantly, more common among respondents than among non-respondents: $10.5 v 9.4 \%$. The difference in the rate of induced abortions between non-respondents and respondents was larger: $15 \cdot 1 v 8 \cdot 1 \%$.

Regarding underreporting of pregnancies among respondents it was found that $8 \%$ of spontaneous abortions and $19 \%$ of induced abortions among the respondents were not reported in the questionnaires. Underreporting was not associated with residential areas.

In all, 100 spontaneous abortions were discovered in the hospital records during the period 1973 to 1981. Eight were only anamnestically reported in the records via a later contact with the medical system. Of the 100 spontaneous abortions found in hospital records, $91 \%$ were also reported in the questionnaires, while only $69 \%$ were found in the hospital discharge registry. Sixteen of the 31 abortions found to be missing in the Registry had however required hospital admission. The remaining spontaneous abortions were either treated at an outpatient clinic (seven cases) or were not treated in hospital at all (eight cases).

The year the spontaneous abortions had taken place was correctly reported in the questionnaire in $92 \%$ of the cases. The reported gestational length of pregnancies resulting in spontaneous abortions was similar in $70 \%$ to the information found in the records (for the same month).

Fifteen spontaneous abortions were reported in the questionnaires only, in addition to the 100 cases found in hospital records. Three were induced abortions, and no information on spontaneous or induced abortion was found in 11 case records. Hospital records were missing for one case. Nine cases were registered as living in Stenungsund and six in Kungälv.

Table II shows the proportion of spontaneous abortions reported in questionnaires and also verified or anamnestically reported in hospital records. Of a total of 105 spontaneous abortions reported in the questionnaire and sought in hospital records, $80 \%$ could actually be verified from these records. A further $7 \%$ were mentioned in the records but lacked medical certification.

Of the 82 answering "yes" to the question concerning a positive pregnancy test, $95 \%$ could be found in the records. The corresponding portion among "yes" respondents to whether a doctor had established the occurrence of the miscarriage was $90 \%$. Ninety-seven per cent of those who gave an affirmative answer to both questions were found in the records. 


\section{Discussion}

Central registers are often used in epidemiological studies of pregnancy outcome as regards such outcome variables as birth weight, perinatal death and malformations. In most countries, however, questionnaire or interview data must be used to study the rate of spontaneous abortion. In most methodological studies made so far concerning the appropriateness of information sources, data are collected from among different occupational groups and not from a general population. Rosenberg et al $^{1}$ reported that the response rate in occupational studies of spontaneous abortion varied between approximately $50 \%$ and $95 \%$. The response rate in this study was $79 \%$, which is close to the results in Swedish epidemiological studies of occupational groups, where the same method is used. ${ }^{1112}$ The response rate was lowest among women older than 35 years of age, ie, among women who in general have terminated their reproductive career.

The pregnancies reported in questionnaires were compared to data in registers and hospital records in this study. It is likely that these sources are reliable as regards the number of births, while it is possible that spontaneous and induced abortions are not found in hospital records. A spontaneous abortion which was not medically diagnosed or an induced abortion performed in a place other than where the woman lived is not necessarily revealed at later contact with the medical care system.

On the average, non-respondents had more pregnancies and primarily induced abortions, but also more spontaneous abortions and births, as compared to respondents. The proportion of women who had never given birth was highest among respondents. The difference in the rate of induced abortions among respondents and nonrespondents was of the same size as in similar reproductive studies among occupational groups. ${ }^{1112}$

It was previously observed in one occupational study that the outcome among non-responders heavily influenced the result of the whole cohort. ${ }^{4}$ Thus analysis of pregnancies among nonrespondents is always desirable.

An underreporting of spontaneous and especially of induced abortions was demonstrated in this study and has also been observed in previous occupational studies. Wilcox and Horney ${ }^{13}$ found in a study of $\mathbf{3 4 8}$ women that only $75 \%$ of spontaneous abortions were recalled. Gestational age at the time of abortion and the time lapse since the abortions were the major determinants of recall. Underreporting is thus a potential source of bias. In this study, however, there was no association between place of residence and underreporting of pregnancies.

Of the spontaneous abortions reported in the hospital records, $69 \%$ were also found in the hospital discharge registry. The absence of spontaneous abortions in the registry were related to length of gestation; early abortions were more often missing. Similar results have been reported from the Finnish hospital discharge registry. ${ }^{9}$

As personal identification number is not available in the Swedish registry at the present time, it is thus likely that questionnaire studies will be of even greater importance in Sweden in the future. A comparison with information in hospital records is therefore necessary in order to evaluate the appropriateness of the postal questionnaire as a source of information.

It has previously been shown that the presence of unverified spontaneous abortions is a potential source of bias in occupational studies. ${ }^{7}$ In this study $80 \%$ of the spontaneous abortions reported in the questionnaire could be verified and a further $7 \%$ were anamnestically reported in the records. Thus $13 \%$ of the spontaneous abortions reported could not be found. This proportion was only $5 \%$ among those women who reported that they had had a positive pregnancy test before the abortion. If the woman also reported that the diagnosis was confirmed by a doctor, the proportion of spontaneous abortions not found in hospital records was reduced to $3 \%$. Thus by adding two complementary questions the proportion of verified or anamnestically reported abortions increased from $87 \%$ to $97 \%$.

Joffe discussed the advantage of using a standard method for research on reproductive effects of occupation. ${ }^{14}$ Based upon the results from the Swedish study, it is recommended that the two complementary questions on spontaneous abortions be included in such a questionnaire.

It is concluded that questionnaire reported spontaneous abortions in a general population can be accepted without verification if the woman has also answered affirmatively to the questions concerning a positive pregnancy test and whether a doctor had established the occurrence of the miscarriage. The previously made recommendation that all spontaneous abortions reported in questionnaires should be verified ${ }^{7}$ can thus be restricted to the remaining cases.

This study was supported by a grant from the Swedish Medical Research Council.

1 Rosenberg MJ, Feldblum PJ, Marshall EG. Occupational influences on reproduction: a review of recent literature. $f$ Occup Med 1987; 29: 584-91

2 Axelsson G. Selection bias in studies of spontaneous abortion among occupational groups. $\mathcal{F}$ Occup Med 1984; 26: 525-8.

3 Joffe $M$. Biases in research on reproduction and women's work. Int $\Im$ Epidemiol 1985; 14: 118-23.

4 Axelsson G, Rylander R. Exposure to anaesthetic gases and spontaneous abortions: response bias in a postal spontaneous abortions: response bias in a po

5 Ericson A, Källén B. An epidemiological study of work with video screen and pregnancy outcome. A case-control study. Am F Ind Med 1986; 9: 459-75.

6 McDonald AD, McDonald JC, Armstrong B, Cherry N, Nolin AD, Robert $D$. Work with visual display units in pregnancy. Br $\mathcal{F}$ Ind Med 1988; 45: 509-15.

7 Axelsson G, Rylander R. Validation of questionnaire reported miscarriage, malformation and birth weight. Int $\mathcal{f}$ Epidemiol 1984; 13: 94-8.

8 Heidam LZ, Olsen J. Self-reported data on spontaneous abortions compared with data obtained by computer linkage with the hospital registry. Scand $\mathscr{f}$ Soc Med 1985 13: $159-63$.

9 Lindbohm M-L, Hemminki K. Nationwide data base on medically diagnosed spontaneous abortions in Finland. Int f Epidemiol 1988; 17: 568-73.

10 Axelsson G, Molin I. Outcome of pregnancy among women living near petrochemical industries in Sweden. Int $J$ living near petrochemical
Epidemiol 1988; 17: 363-9.

11 Axelsson G, Lütz C, Rylander R. Exposure to solvents and outcome of pregnancy in university laboratory employees. outcome of pregnancy in university

12 Axelsson G, Rylander R, Molin I. Outcome of pregnancy in Axelsson $\mathbf{G}$, Rylander $\mathrm{R}$, Molin $\mathrm{I}$. Outcome of pregnancy in relation to irregular and incon

13 Wilcox AJ, Horney LF. Accuracy of spontaneous abortion recall. Am $₹$ Epidemiol 1984; 120: 727-33.

14 Joffe $M$. Advantages of a standard method for research on reproductive effects of occupation. $\mathcal{F}$ Epidemiol Community Health 1988; 42: 209-12. 